\title{
A parametric study of influence of material properties on car cabin environment
}

\author{
Jan Pokorny ${ }^{1, a}$, Jan Fiser ${ }^{1}$ and Miroslav Jicha ${ }^{1}$ \\ ${ }^{1}$ Brno University of Technology, Faculty of Mechanical Engineering, Energy Institute, Technicka 2896/2, Brno, \\ Czech Republic, pokorny.j@fme.vutbr.cz
}

\begin{abstract}
Recently the author presented the paper describing a car cabin heat load model for the prediction of the car cabin environment. The model allowed to simulate a transient behavior of the car cabin, i.e. radiant temperature of surfaces, air temperature and relative humidity. The model was developed in Dymola and was built on the basic principles of thermodynamics and heat balance equations. The model was validated by experiments performed on the Škoda Felicia during various operational conditions. In this paper the authors present a parametric study investigating influence of material properties on a car cabin environment. The Matlab version of the car cabin heat load model has been developed and used. The model was extended by simple graphical user interface and it was deployed into the stand alone executable application. The aim of this parametric study is to identify most important material properties and its effect on the cabin environment during specific operational conditions of car. By means of a sensitive analysis it can identified which material parameters have to be defined precisely and which parameters are not so important for the prediction of the air temperature inside cabin.
\end{abstract}

\section{Introduction}

The input/output sensitivity analysis is very important process during designing of the new computational model. In this paper authors present a sensitivity analysis of "Operational heat balance model with parameterized geometry for the prediction of car cabin heat loads", which was recently presented in [1]. The mentioned model is designed for the fast prediction of the car cabin environment during various operating conditions. Such kind of computational tool is useful during early stage of the new car and its HVAC system design. Main inputs of the model are weather data, operating conditions of car, geometry and material composition. Main outputs of the model are air zone and surface temperatures, air zone relative humidity and also car cabin heat load.

The presented study is focused on the influence material properties on a car cabin environment. The effect of material properties on the cabin environment was investigated by many authors, i.e. influence of radiation properties of car painting [2, 3] or car glazing [4].

A motivation for this parametric study was that the operational heat balance model and other commercial software require a detailed data about material composition and its physical properties. The question is how accurate these data should be to provide reasonable results?

\footnotetext{
${ }^{\mathrm{a}}$ Corresponding author: pokorny.j@fme.vutbr.cz
}

\section{Methods}

For the parametric study was chosen two scenarios: parking (in summer) and driving (in winter). For both cases the material modifications were done to identify its effect on the car cabin environment, and air zone temperature especially. The parameters as conductivity, specific heat capacity, solar transmissivity of glazing, solar absorptivity and emissivity of car painting were altered to carry out its effect on the air temperature inside cabin.

The parametric study was done by using a new Matlab model instead of the original Dymola model [1]. The basic principles of the heat transfer simulations were preserved; it is a heat balance model defined by the set of ordinary differential equations. These equations describe accumulation of heat in car cabin materials, mixing of ventilation of air in cabin, etc. The Matlab version was extended by graphical user interface, more detailed parameterized geometry and it was compiled into the standalone executable application. In the Matlab version, there is also possible to setup more detailed composition of cabin wall layers.

\subsection{Geometry}

The presented study was done for the car Škoda Felicia Combi with dark blue painting, see Figure 1. The real geometry was simplified into a parameterized one, see 
Figure 2. The parameterized car cabin geometry was generated by a set of geometrical parameters to obtain 3D geometry in .nas (nastran) and .mat file format. The nastran file was processed in Star-CCM+ to identify radiation view factors of generated geometry and the .mat file format was used for Matlab model processing. The .mat file contains data about triangular mesh defining all faces and its normal vectors. The set of faces forms the particular cabin parts, see different colors in Figure 2. The car was split into 31 parts, however for the heat transfer calculation was considered only 18 parts surroundings' the cabin cavity, see the list of car cabins in Table 1.

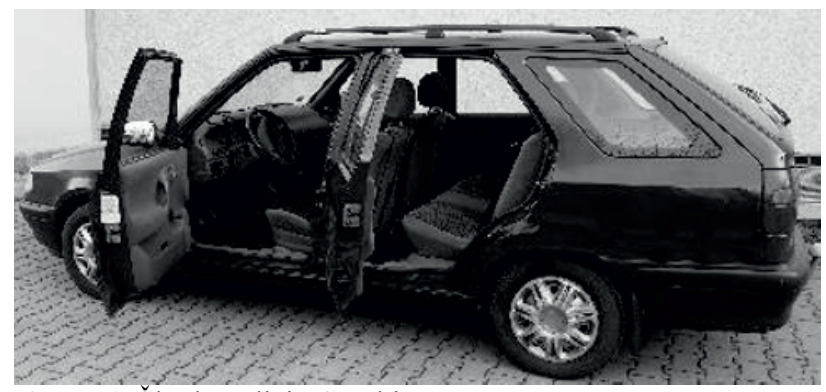

Figure 1. Škoda Felicia Combi.

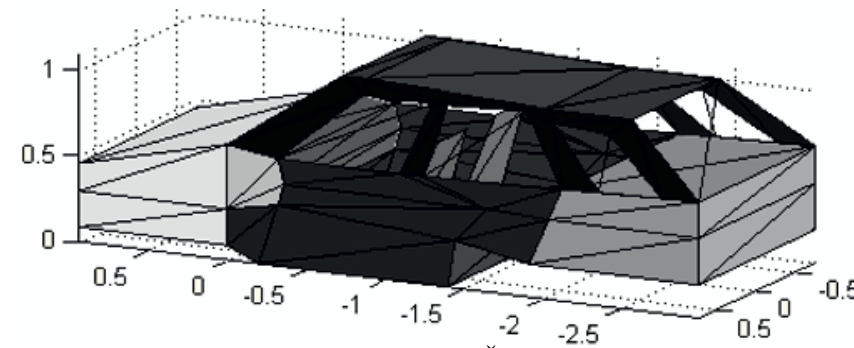

Figure 2. Parameterized geometry of Škoda Felicia Combi.

\subsection{Material Composition}

A default material composition for Škoda Felicia Combi was identified from the real car and material properties were estimated based on the literature survey of material properties. In Table 1 is defined composition of the each part by material identity (IDM) and thickness $\delta$. In the case of Škoda Felicia overall cabin part properties were estimated directly, however generally the model allows to define multilayered composition of particulars parts. In Table 2, there is material database describing material properties of the material defined by its IDM. All values should be close to the reality, only the values of conductivity for the materials FE-7 were artificially changed to the almost zero; to considered the fact that dashboard temperature is not influenced by the conduction from engine space at all (dashboard has a large air cavity). In Table 2, there are values of material properties for exterior surfaces as longwave emissivity $\varepsilon$, solar transmissivity $t$ and solar absorptivity $a$. The density $\rho$, conductivity $k$ and specific heat capacity $c$ are integrated into one value, which takes into account layer structure of the cabin part (i.e. in side doors, there are considered air gap, metal and plastic construction). Radiation properties of interior opaque surfaces were considered in simplified way as follows: $a=1, t=0, \varepsilon=1$.
Table 1. Material composition.

\begin{tabular}{|rc|lr|}
\hline \multicolumn{1}{|c|}{ IDP } & Name & IDM & $\delta[\mathrm{mm}]$ \\
\hline 1 & Windshield & FE-1 & 5 \\
2 & Rear window & FE-2 & 4 \\
3,4 & Side windows L,R & FE-2 & 4 \\
5,6 & Side pillars L,R & FE-3 & 20 \\
7,8 & Side doors L,R & FE-3 & 20 \\
9,10 & Roof (Sunroof) & FE-4 & 35 \\
11 & Floor & FE-5 & 30 \\
12 & Firewall & FE-6 & 20 \\
13,14 & Dashboard up., lo. & FE-7 & 20 \\
15,16 & Front seat L,R & FE-8 & 160 \\
17 & Rear seat & FE-8 & 160 \\
18 & Rear shell & FE-9 & 4 \\
\hline
\end{tabular}

Table 2. Material database (exterior surfaces).

\begin{tabular}{|c|c|c|c|c|c|c|}
\hline IDM & $\begin{array}{c}\rho \\
{\left[\mathrm{kg} / \mathrm{m}^{3}\right]}\end{array}$ & $\begin{array}{c}k \\
{[\mathrm{~W} / \mathrm{mK}]}\end{array}$ & $\begin{array}{c}c \\
{[\mathrm{~J} / \mathrm{kgK}]}\end{array}$ & $\begin{array}{c}a \\
{[-]}\end{array}$ & $\begin{array}{c}t \\
{[-]}\end{array}$ & $\begin{array}{c}\varepsilon \\
{[-]}\end{array}$ \\
\hline FE-1 & 2400 & 0.6 & 830 & 0.43 & 0.52 & 0.8 \\
\hline E-2 & 2500 & 0.9 & 800 & 0.39 & 0.55 & 0.8 \\
\hline E-3 & 110 & & 580 & 0.78 & 0 & 0.85 \\
\hline FE-4 & 270 & 0.054 & 560 & 0.78 & 0 & 0.85 \\
\hline FE-5 & 480 & 0.041 & 800 & 0.78 & 0 & 0.85 \\
\hline FE-6 & 600 & 0.042 & 860 & 0.8 & 0 & 0.85 \\
\hline FE-7 & 800 & 0.0001 & 1700 & 0.95 & 0 & 0.85 \\
\hline FE-8 & 320 & 0.035 & 1300 & 0.8 & 0 & 0.85 \\
\hline E-9 & 1100 & 0.035 & 1300 & 0.8 & 0 & 0.85 \\
\hline
\end{tabular}

\subsection{Sensitivity analysis}

The car cabin environment is given by a type of the car, its operational conditions and outside ambient conditions. In this paper the object of interest is an influence of the material data on the car climate during various conditions. The sensitivity study was done for the following parameters:

- $\quad$ solar transmissivity of glazing $t=0,0.2,0.4,0.6,0.8,1$

- $\quad$ solar absorptivity of car painting $a=0,0.2,0.4,0.6,0.8,1$

- longwave emissivity of car painting $\varepsilon=0,0.2,0.4,0.6,0.8,1$

- thermal conductivity of all parts $k^{*}=0.2 \cdot \mathrm{k}, 0.5 \cdot \mathrm{k}, 1 \cdot \mathrm{k}, 2 \cdot \mathrm{k}, 5 \cdot \mathrm{k}$

- $\quad$ specific heat capacity of all parts $c^{*}=0.2 \cdot \mathrm{c}, 0.5 \cdot \mathrm{c}, 1 \cdot \mathrm{c}, 2 \cdot \mathrm{c}, 5 \cdot \mathrm{c}$

First three quantities were varying by a set of values, and a variation of the last two quantities $k^{*}, c^{*}$ were defined by set of multipliers. Without doubt, the effect of specific physical parameter will be different for various type of boundary conditions. Thus in this parametric study were chosen two very different real operating conditions. 
- $\quad$ summer parking 13.9.2011, see [1]

- winter driving 26.1.2012, see [5]

\section{Results}

In this chapter are presented results of the sensitivity analysis. A real time of experiments was $82303 \mathrm{~s}$ for parking and $4830 \mathrm{~s}$ for driving. A computational time was $47.5 \mathrm{~s}, 18.4 \mathrm{~s}$ respectively. The low computational time of this tool allow to process a large batch file containing various combinations of model input parameters. In the paper are presented results of various simulations with modified material data; 30 simulations for parking and 30 simulations for driving test case.

\subsection{Summer parking}

The car was parked on the parking lot almost 24 hours.

- Ambient temperature: from $14.2{ }^{\circ} \mathrm{C}$ (at night) to $27.8^{\circ} \mathrm{C}$, during day over $25^{\circ} \mathrm{C}$

- Solar intensity: clear day with max. $650 \mathrm{~W} / \mathrm{m}^{2}$

- Car speed $0 \mathrm{~km} / \mathrm{h}$, no ventilation and no crew

During summer parking test case the most sensitive material properties were identified radiation properties as transmissivity of glazing and absorptivity of car painting, because of the high solar loads during day, see Figure 3 and Figure 4. Longwave emmisivity of car painting is in such conditions less important, see Figure 5.

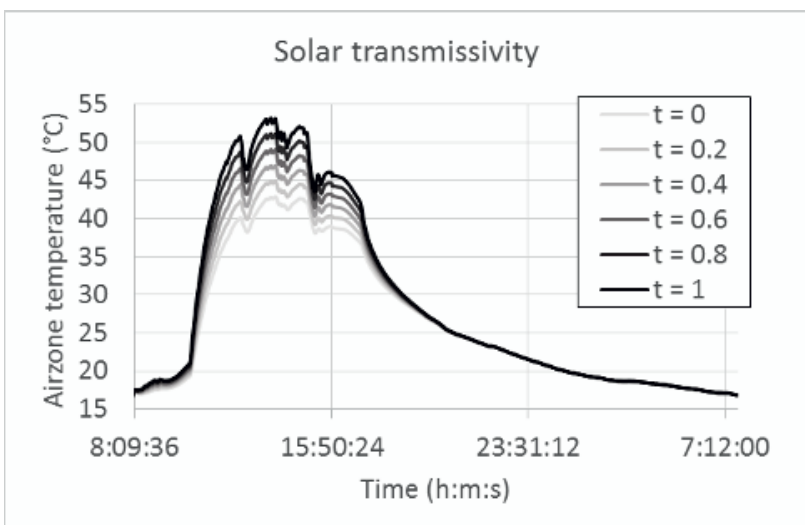

Figure 3. Solar transmissivity of car glazing.

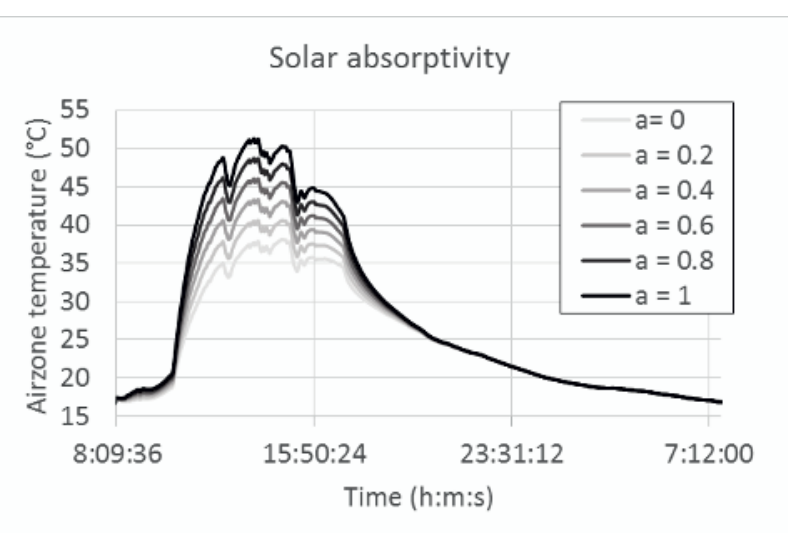

Figure 4. Solar absorptivity of car painting.
Specific heat capacity is also very important, see Figure 6. High specific heat capacity expresses high ability of heat accumulation in materials, which cause damping of the cabin air zone temperature during transient change of ambient environment conditions.

In parking test case the air zone temperature is almost non-sensitive respect to the change of conductivity, see Figure 7. It is mainly due to the low difference between outside and inside temperature during the night and a very dominant solar radiation during the day.

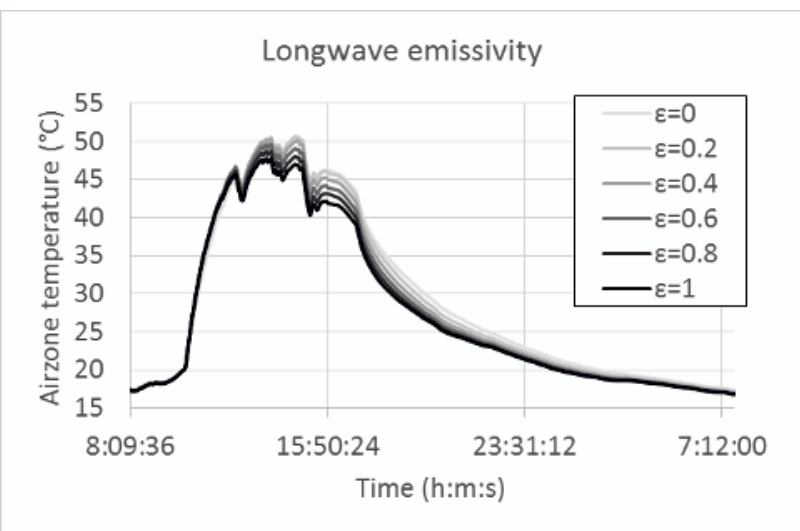

Figure 5. Longwave emissivity of car painting.

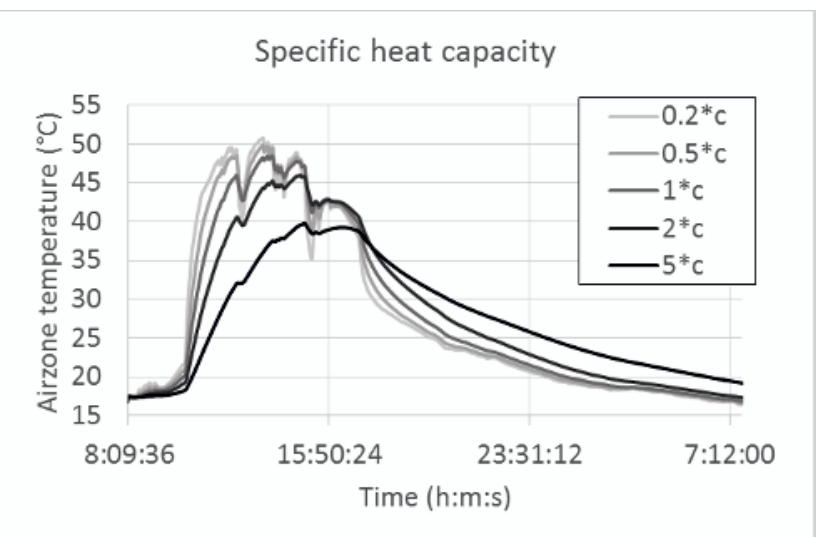

Figure 6. Specific heat capacity of all cabin parts.

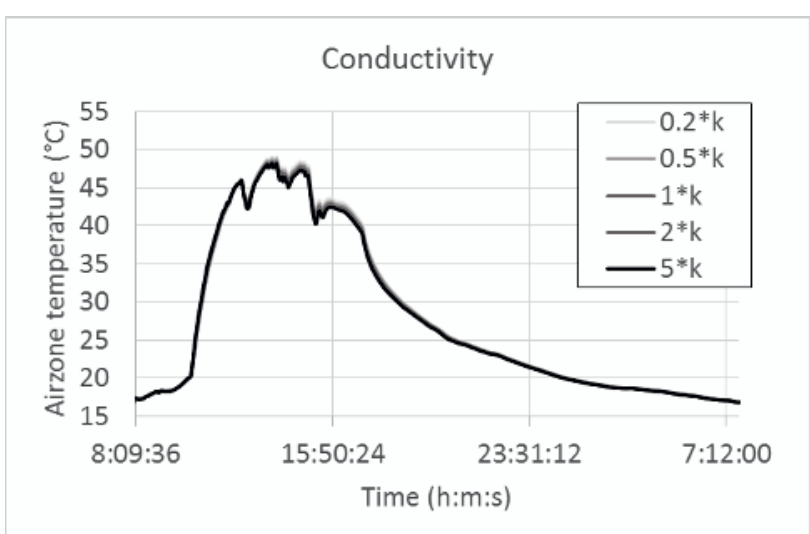

Figure 7. Thermal conductivity of all cabin parts.

\subsection{Winter driving}

The car cabin temperature before the start of a winter test was close to the ambient temperature. Immediately after start driving the heating system was switch on to deliver warm air through the outlets inside the cabin. 
- Average ambient temperature: $+0.5^{\circ} \mathrm{C}$

- Solar intensity: $48 \mathrm{~W} / \mathrm{m}^{2}$ (only diffuse)

- Car speed: maximal $86.8 \mathrm{~km} / \mathrm{h}$, average $54.6 \mathrm{~km} / \mathrm{h}$

- Ventilation: volumetric flow $27 \mathrm{l} / \mathrm{s}$, air temp. $36^{\circ} \mathrm{C}$

- Crew - 2 occupants (source of heat and humidity)

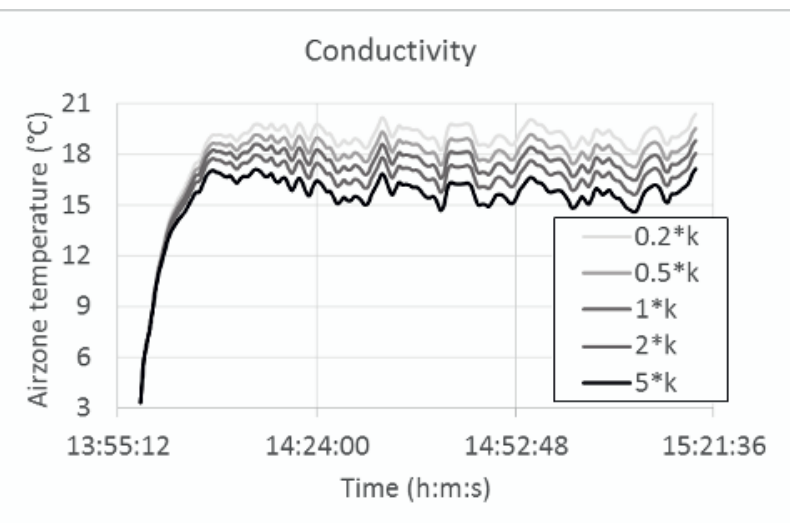

Figure 8. Thermal conductivity of all cabin parts.

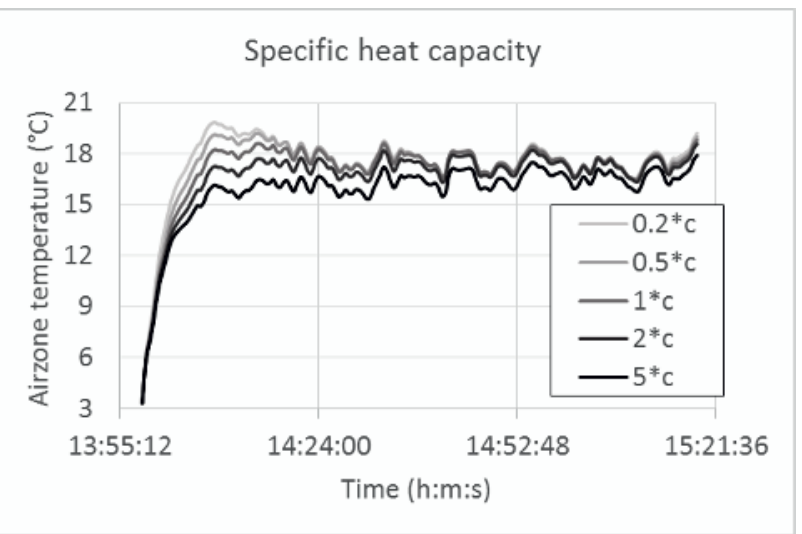

Figure 9. Specific heat capacity of all cabin parts.

Because solar intensity was too low, the influence of the solar loads on the cabin air temperature can be neglected. The very important is specific heat capacity and conductivity; see Figure 8 and Figure 9. A thermal conductivity of cabin parts is more important in stabilized stationary conditions, on the contrary a specific heat capacity is the most important during and mainly immediately after transient changes of boundary conditions. Similarly as in parking test case the change of air zone temperature is not too sensitive to the change of emissivity of car painting, see Figure 10.

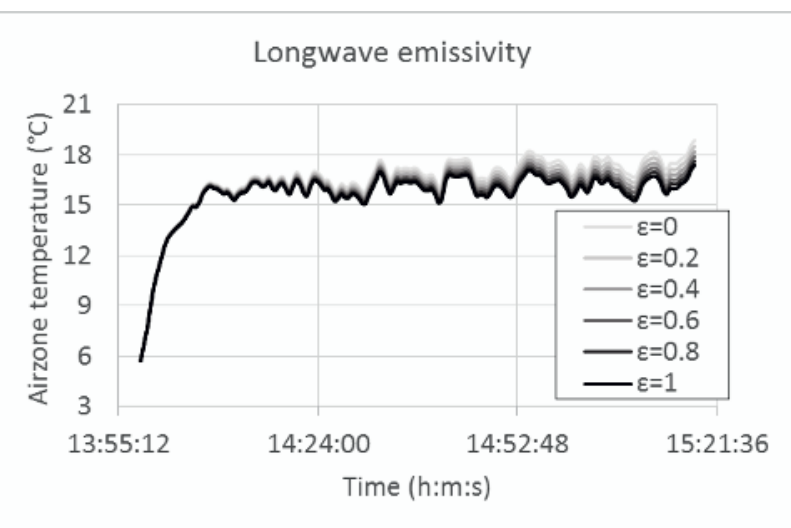

Figure 10. Longwave emissivity of car painting.

\section{Conclusion}

The parametric study of the model was presented for the Śkoda Felicia Combi car in situations of the summer parking and the winter driving. The study shows, which material properties were identified as important for accuracy of the model prediction and which are less important with small influence on prediction of results. It was confirmed that a sensitivity of air zone temperature respect to the material properties is very dependent on the specific operating conditions.

One of the most important material property for all operating conditions is specific heat capacity. The accurate value of specific heat capacity is important to capture dynamical behavior of the car cabin environment. Transient changes of weather, car speed and azimuth, ventilation setup are typical for real operating conditions.

In summer season the solar transmissivity of car painting and solar absorptivity of glazing are dominant material properties. This effect is more evident during parking or low speed driving in a city traffic. The accuracy of thermal resistance of cabin parts is important in the winter season when the ambient temperature is very low. This effect is more evident during high speed driving. The accuracy of longwave emissivity is less important than other mentioned material properties, but still it should be take into account during modeling of the car cabin heat load mainly during extreme cold weather conditions.

The plans to the future are to finish the extended model and validate it for the Škoda Octavia $3^{\text {rd }}$ generation.

\section{Acknowledgements}

Financial support from the Czech national project of Josef Bozek Competence Centre for Automotive Industry, TE01020020 and Netme centre CZ.1.05/2.1.00/01.0002 is gratefully acknowledged.

\section{References}

1. J. Pokorny, J. Fiser, M. Jicha, Int. J. of Vent. 11 (4), 393 (2013)

2. R. Levinson, Pan H., G. Ban-Weiss, P. Rosado, et al. Applied Energy 88 (12), 4343 (2011)

3. J. Rugh, R. Farrington and J. Boettcher, SAE Technical Paper 2001-01-1721 (2001)

4. R. Farrington, J. Rugh and G. Barber, SAE Technical Paper 2000-01-2694 (2000)

5. J. Fiser, J. Pokorny, D. Podola, M. Jicha, Experimental investigation of car cabin environment during real traffic conditions. 31. Setkání kateder mechaniky tekutin a termomechaniky, Mikulov, 51-54 (2012) 